\title{
ECONOMIC CONTIGUITY (PART ONE) PHYSICAL CONSTRUCTION COST
}

\author{
Dwi Jayanti ${ }^{1}$, Diah Daniaty ${ }^{2}$, Resti Fitri ${ }^{3}$, Khoirotun Nisa ${ }^{4}$ \\ ${ }^{1}$ STIS 49 Economic Division, Indonesia \\ ${ }^{2}$ STIS 50 Computer Division, Indonesia \\ ${ }^{3}$ STIS 51 Computer Division, Indonesia \\ ${ }^{4}$ STIS 53 Computer Division, Indonesia \\ dwijayanti.stis49@gmail.com
}

Law number 33 year 2004 on financial balance is further explained by Presidential decision that regional allocation fund is based on a fixed amount. If particular regions receive more than they deserve, other regions receive less than they expect. Allocated fund is weighted among others by index of physical construction cost (IKK). The author and co-authors propose a way for IKK be closer to reality. Selected components of physical construction in IKK is applied to all regions. It turns out that regions considered as rich may be in different physical cost structure from not so rich regions. Further for certain few important components cost may be subject to regional wealth comparison. We found at least one natural component in western region and one manufactured component in eastern region for possible revision. Current regional computerized raw data entry is standardized by single national custom-made application software. Cut off point for entry acceptance is applied to all regions which sometimes violates regional specific characteristics. Once raw data is rejected, it is difficult to trace back the real raw data which may be closer to the truth. Therefore we rely on spatial contiguity to recover unentered rejected raw data. Theory of composite index suggest that a figure is not only produced for publication but also for analytical soundness. That is introducing another unfamiliar step for most regional employee and regional official. Since raw data is always available in head office, it is a feasible practice to evaluate regional raw data prior to aggregation in head office beyond most regional insight.

\section{DISCLAIMER}

The views expressed here are those of the individual author and co-authors and not necessarily those of STIS or its board, or officers, or staff. 